\title{
Enriching Trace Level Adsorption Affinity of As3+ ion using Hydrothermally Synthesized Iron-Doped Hydroxyapatite Nanorods
}

Sandeep Eswaran Panchu

Anna University Chennai

Saranya Sekar

Anna University Chennai

Vani Rajaram

Meenakshi College for Women

Elayaraja Kolanthai

University of Central Florida

Sarojini Jeeva Panchu

University of the Free State

Hendrik C. Swart

University of the Free State

NARAYANA Kalkura ( $\nabla$ kalkura@yahoo.com )

Anna University Chennai https://orcid.org/0000-0001-5777-2907

\section{Research Article}

Keywords: Hydrothermal, colloidal stability, surface charge, Surface complexation, As3+ adsorption, Adsorption isotherm

Posted Date: June 18th, 2021

DOl: https://doi.org/10.21203/rs.3.rs-630778/v1

License: (c) (i) This work is licensed under a Creative Commons Attribution 4.0 International License. Read Full License

Version of Record: A version of this preprint was published at Journal of Inorganic and Organometallic Polymers and Materials on September 16th, 2021. See the published version at https://doi.org/10.1007/s10904-021-02103-0. 


\title{
Enriching trace level adsorption affinity of $\mathrm{As}^{3+}$ ion using hydrothermally synthesized iron- doped hydroxyapatite nanorods
}

Sandeep Eswaran Panchu ${ }^{1}$, Saranya Sekar ${ }^{1}$, Vani Rajaram ${ }^{2}$, Elayaraja Kolanthai ${ }^{3}$, Sarojini Jeeva Panchu $^{4}$, Hendrik C.Swart ${ }^{4}$, Narayana Kalkura Subbaraya ${ }^{1 *}$

${ }^{1}$ Crystal Growth Centre, Anna University, Chennai, 600 025, Tamil Nadu, India.

${ }^{2}$ Meenakshi College for Women, Kodambakkam, Chennai, 600024. Tamil Nadu, India.

${ }^{3}$ Department of Materials Science \& Engineering, Advanced Materials Processing and Analysis Center, University of Central Florida, Orlando, FL, USA

4 Department of Physics, University of the Free State, PO Box 339, Bloemfontein, 9300, South Africa.

\section{*Corresponding Author}

Prof. S. Narayana Kalkura

Crystal Growth Centre

Anna University

Chennai- 600 025, Tamilnadu, India

Tel. No: +91-44-22358335

Email address: kalkura@gmail.com

\begin{abstract}
Contamination of arsenic in the form of arsenite $\left(\mathrm{As}^{3+}\right)$ and arsenate $\left(\mathrm{As}^{5+}\right)$ in potable water causes serious illness in the human body even at a very low concentration $(10 \mu \mathrm{g} / \mathrm{L})$. As ${ }^{3+}$ is comparatively 60 times more toxic than $\mathrm{As}^{5+}$ species. Hence, this work is focused on the preparation of adsorbents for efficient removal of $\mathrm{As}^{3+}$ with higher adsorption affinity at trace level $(\leq 50 \mu \mathrm{g} / \mathrm{L})$. Here, iron-doped hydroxyapatite (Fe-HAp) synthesized by hydrothermal technique is employed as an efficient adsorbent. A very less quantity of $\mathrm{Fe}^{2+}$ ion $(0.5 \mathrm{wt} \%)$ is incorporated in the tetrahedral and octahedral sites of the HAp lattice along the c-axis which lead to drastic reduction in particle size (400\%) and enhancing the specific surface area (105\%), colloidal
\end{abstract}


stability, and adsorption affinity. The maximum adsorption capacity of $\mathrm{As}^{3+}$ is $139 \pm 2 \mu \mathrm{g} / \mathrm{g}$ and $183 \pm 2 \mu \mathrm{g} / \mathrm{g}$ for HAp and Fe-HAp, respectively. The adsorption rate of Fe-HAp is very rapid which is $538 \%$ higher compared to HAp and also the $\mathrm{As}^{3+}$ adsorption affinity or sensitivity $(0.71 \mu \mathrm{g} / \mathrm{L})$ significantly improved 83-99\% when compared to the adsorbents reported in the previous literature so far. The monolayer adsorption of $\mathrm{As}^{3+}$ is purely strong chemisorption as confirmed by the Langmuir and Dubinin-Radushkevich (DKR) isotherm. The structure and morphology of HAp and Fe-HAp remain unchanged after the adsorption of $\mathrm{As}^{3+}$ ions and also no secondary toxic products were observed. Hence, the above results reveal Fe-HAp as an efficient and low-cost adsorbent for removal of highly toxic $\mathrm{As}^{3+}$ ions at the trace level.

Keywords: Hydrothermal, colloidal stability, surface charge, Surface complexation, As ${ }^{3+}$ adsorption, Adsorption isotherm

\section{Introduction}

Arsenic (As) is a familiar toxic metal ion that can be found in groundwater as a contaminant. The World Health Organization (WHO) recommended that the limit of arsenic in drinking water is $\leq 10$ $\mu \mathrm{g} / \mathrm{L}$. However, more than 60 million peoples are said to be affected by arsenic contamination, which is exceeding WHO limits [1-5]. Consuming of Arsenic contaminated water causes carcinogenic effects in the skin, urinary bladder, liver, kidney, and lung [6-9]. Generally, Arsenic has four different chemical forms in an aquatic environment based on the oxidation state $-3,0,+3$, and +5 . The existence of arsenic in 0 and -3 oxidation states in water is extremely rare, while +3 and +5 states are prominently found in the natural water source, which strongly depends on the redox reaction and $\mathrm{pH}$ condition [10,11]. In groundwater, $\mathrm{As}^{3+}$ is found in neutral species such as $\mathrm{As}(\mathrm{OH})_{3}, \mathrm{H}_{3} \mathrm{AsO}_{3}, \mathrm{As}(\mathrm{OH})_{4}{ }^{-}, \mathrm{AsO}_{2} \mathrm{OH}^{2-}$, and $\mathrm{AsO}_{3}{ }^{3-}$, whereas $\mathrm{As}^{5+}$ is found in anionic forms such as $\mathrm{AsO}_{4}{ }^{3-}$ or $\mathrm{H}_{2} \mathrm{AsO}^{-}$or $\mathrm{HAsO}_{4}{ }^{2-}$ [12,13]. In comparison, the prevalence of $\mathrm{As}^{3+}$ contaminated groundwater is approximately 67-99\% higher than $\mathrm{As}^{5+}$ ions and the toxicity rate of $\mathrm{As}^{3+}$ is 60 times greater than the $\mathrm{As}^{5+}[14]$. In addition, $\mathrm{As}^{3+}$ shows less adsorption affinity than $\mathrm{As}^{5+}$ because $\mathrm{As}^{3+}$ is a neutral compound, whereas $\mathrm{As}^{5+}$ is an anionic compound. The anionic compound has improved attractive force between the adsorbent and adsorbate ions [7].

Various technologies have been applied to remove the arsenic from contaminated water, such as chemical precipitation, flocculation, ion exchange and reverse osmosis $[9,12,13]$. But, these 
technologies have limitations when implementing them into large-scale processes. The membrane technology, a reverse osmosis process requires high electric power and skilled technicians required to operate. Likewise, the flocculation, ion exchange, and precipitation methods are problematic due to their complexities in the disposal of secondary products [13]. Recently, the adsorption technique has emerged as an effective alternative method, because it is a simple and cost-effective method for the removal of arsenic [15-17]. A variety of adsorbents were employed to removing arsenic from water. They are iron-oxide-coated quartz (IOCQ), biochar, magnetic Fe-hydrotalcite, activated alumina, sulfate-modified iron oxide-coated sand [18-22] etc.,

At the same moment, nano-sized adsorbents were used to remove the metal ions because they a have high surface area, adsorption capacity, and affinity. In this work, calcium phosphate (CaP) based adsorbent HAp $\left[\mathrm{Ca}_{10}\left(\mathrm{PO}_{4}\right)_{6}(\mathrm{OH})_{2}\right]$ has been used to remove arsenic from water. Because, HAp is highly biocompatible, porous in nature, relatively inexpensive, easy to modify the structural and morphological characteristics based on synthesis routes, and ensures safe drinking water [23]. Despite, still HAp has a lack of adsorption affinity of arsenic was observed. Hence, the $\mathrm{Fe}^{2+}$ ions are introduced into the HAp lattice which is enhanced the adsorption affinity and their capacity. Because it has the capability to control arsenic mobility, and higher adsorption affinity of arsenic ions [24-27].

Herein, the removal of highly toxic $\mathrm{As}^{3+}$ ion at trace level using hydrothermally synthesized nanosized Fe-HAp was employed as an adsorbent to overcome the above mentioned problem. The incorporation of the $\mathrm{Fe}^{2+}$ ion improves adsorbent characteristic features. That results show the narrow mesoporous structure, reduction of particle size, higher surface area, and higher colloidal stability as shown in Fig. 1. Also, this work elucidates the importance of colloidal stability and zero point charge of the adsorbent. The maximum adsorption capacity was found by the batch adsorption process. The nature of the adsorption process was discussed using Langmuir, Freundlich, and DKR isotherm. Ultimately the aim of this work is to enhance trace level adsorption affinity, $\mathrm{As}^{3+}$ adsorption capacity, and maintain the water quality.

\section{Experimental section}

\subsection{Materials and methods}


Calcium nitrate tetrahydrate $\left(\mathrm{Ca}\left(\mathrm{NO}_{3}\right)_{2} .4 \mathrm{H}_{2} \mathrm{O}\right)$, diammonium hydrogen orthophosphate $\left(\left(\mathrm{NH}_{4}\right)_{2} \mathrm{HPO}_{4}\right)$, Iron (II) chloride $\left(\mathrm{FeCl}_{2}\right)$, Hydrochloric acid $(\mathrm{HCl})$, Ammonia solution $\left(\mathrm{NH}_{4} \mathrm{OH}\right)$, and Sodium arsenite $\left(\mathrm{NaAsO}_{2}\right)$. All the chemicals were purchased from Merck analytical grade. Triple distilled water was used to prepare adsorbent and adsorbate ion.

\subsection{Synthesis of HAp and Fe-HAp}

$1 \mathrm{M}$ of calcium nitrate tetrahydrate and $0.6 \mathrm{M}$ of di-ammonium hydrogen orthophosphate were dissolved in $100 \mathrm{~mL}$ of triple distilled water in separate beakers. $1 \mathrm{M}$ of calcium nitrate tetrahydrate was added drop-wise into $0.6 \mathrm{M}$ of diammonium hydrogen orthophosphate by maintaining the $\mathrm{pH}$ of the product solution at 10 using ammonia to synthesize HAp. The obtained precipitated solution was continuously stirred for $2 \mathrm{~h}$ and transferred into a $100 \mathrm{~mL}$ Teflon-lined stainless-steel autoclave and kept in an oven at $150^{\circ} \mathrm{C}$ for $36 \mathrm{~h}$. Subsequently, the autoclave was allowed to reach room temperature and the solution was centrifuged with triple distilled water to remove the unreacted ammonia from the precipitated HAp. Finally, the collected precipitates were dried in a vacuum oven at $80^{\circ} \mathrm{C}$ for $24 \mathrm{~h}$. The Fe-HAp was synthesized by mixing $0.1 \mathrm{M}$ of ferric chloride with $1 \mathrm{M}$ of calcium nitrate tetrahydrate. The rest of the synthesis procedure is the same as the preparation of HAp described above.

\subsection{Characterizations}

Powder X-ray diffraction (XRD) of the synthesized adsorbent was recorded by Rigaku Ultima IV $\mathrm{X}$-ray diffractometer equipped with $\mathrm{Cu} \mathrm{K}_{\alpha}$ radiation $(\lambda=0.154 \mathrm{~nm})$ in the $2 \theta$ range of $10^{\circ}$ to $70^{\circ}$ with scanning step size of $0.02^{\circ}$. The functional group of the adsorbent was analyzed by Fourier transform infrared spectrometer (FT-IR-JASCO-6300) using the $\mathrm{KBr}$ pellet technique. The adsorbent morphology was obtained using transmission electron microscopy (TEM-PHILIPS-CM 200) and Scanning electron microscopy (SEM-Carl Zeiss-EVO 180). The specific surface area, pore size, and pore volume of the adsorbent material were measured by Brunauer-Emmett-Teller (BET) isotherm model by using surface area analyzer-TPD/TPR (Model: Quanta chrome). The adsorbent zeta potential was measured by Dynamic Light Scattering (DLS-Malvern Zetasizer Nano-ZS). The removal capacity of $\mathrm{As}^{3+}$ was evaluated using an Atomic Absorbance spectrometer (AAS-iCE 33-00 from Thermo fisher) equipped with a hydrate generator. The $\mathrm{pH}$ of the solution was measured using a Eutech $\mathrm{pH}$ meter with a sensitivity of 0.01 . 


\section{Batch adsorption study}

$1000 \mu \mathrm{g} / \mathrm{L}$ of $\mathrm{As}^{3+}$ stock solution was prepared from sodium arsenite as a precursor material. The required concentrations were obtained by the dilution of stock solution using triple distilled water. Initially, $100 \mathrm{mg}$ of adsorbents were added to $20 \mathrm{ml}$ of $1000 \mu \mathrm{g} / \mathrm{L}$ of $\mathrm{As}^{3+}$ solution that was used to investigate the effect of contact time ( 0 to $50 \mathrm{~min})$. The rest of the parameters $\mathrm{pH}(7), \mathrm{rpm}(180)$, and temperature $\left(25 \pm 1^{\circ} \mathrm{C}\right)$ were kept constant. After that, the evaluated contact time (10 min) was fixed to subsequent studies on the concentration effect of $\mathrm{As}^{3+}(100 \mu \mathrm{g} / \mathrm{L}$ to $1000 \mu \mathrm{g} / \mathrm{L})$, and the rest of the adsorption parameters were kept constant. The maximum removal capacity of $\mathrm{As}^{3+}$ is measured from Eq. (1). All the experiments were conducted in triplicate with an error percentage of $\pm 1 \%$. After adsorption of $\mathrm{As}^{3+}$, HAp and Fe-HAp were named as HAp-As and Fe-HAp-As.

Adsorption capcity $\left(Q_{e}\right)=\left(C_{o}-C_{f}\right) \times\left(\frac{V}{M}\right)$

Where $Q_{e}$ is the equilibrium adsorption capacity $(\mu \mathrm{g} / \mathrm{g}) . \mathrm{C}_{\mathrm{o}}$ and $\mathrm{C}_{\mathrm{f}}$ are the initial and final concentration of adsorbate solution $(\mu \mathrm{g} / \mathrm{L}) . \mathrm{V}$ and $\mathrm{M}$ are the volume of the solution $(\mathrm{mL})$ and mass of the adsorbent dosage (mg), respectively [28-31].

\subsection{Quantification of $\mathrm{Fe}^{2+}$ ion}

The presence of doping iron in HAp was estimated by dissolving $10 \mathrm{mg}$ of Fe-HAp in $20 \mathrm{ml}$ of $\mathrm{HCl}(0.1 \mathrm{M})$ solution. Furthermore, the concentration of $\mathrm{Fe}^{2+}$ ion released in triple distilled water and $\mathrm{As}^{3+}$ contaminated water was calculated by the following procedure. $100 \mathrm{mg}$ of Fe-HAp was soaked in $20 \mathrm{~mL}$ of triple distilled water and $\mathrm{As}^{3+}$ contaminated water $(\mathrm{pH}=7$; shaking speed $=180$ $\mathrm{rpm})$ at room temperature. After the equilibrium time (10 $\mathrm{min})$, the supernatant solution was tested in AAS.

\section{Result and discussion}

\subsection{X-ray diffraction analysis}

The XRD patterns of the synthesized and $\mathrm{As}^{3+}$ ion adsorbed HAp and Fe-HAp nanoparticles are shown in Fig. 2a. The diffraction pattern of both adsorbents exhibited crystalline nature and matched well with the characteristic peaks of HAp phase in accordance with JCPDS card No. 09- 
$0432[32,33]$. The absence of any significant shift in diffraction peak towards the lower angle confirms that the $\mathrm{Ca}^{2+}$ ion was not substituted by the $\mathrm{Fe}^{2+}$ ions [34]. In HAp, the $a$-axis is positively charged due to the presence of $\mathrm{Ca}^{2+}$ ions, whereas the $c$-axis is negatively charged due to the influence of phosphate and hydroxide ions, which enables the incorporation of cationic $\mathrm{Fe}^{2+}$ ion as shown in schematic representation of Fig. $2 \mathbf{b}[35,36]$. Hence, the doped $\mathrm{Fe}^{2+}$ ions were expected to be incorporated in the interstitial position either at the tetrahedral or octahedral vacancy of hexagonal geometry in [0001] direction along the $c$-axis. The crystallite size, crystallinity, dislocation density, and microstrain of HAp and Fe-HAp could be calculated using the Eqs. (2-5) $[3,37-39]$.

Crystallite $-\operatorname{Size}\left(D_{c}\right)=\frac{K_{B} \lambda}{\beta \cos \theta}$

$\operatorname{Crystallinity}\left(X_{c}\right)=\left(\frac{K_{c}}{\beta}\right)^{3}$

Dislocation $-\operatorname{density}(\delta)=\frac{1}{\left(D_{c}\right)^{2}}$

$\operatorname{Microstarin}(\varepsilon)=\left(\frac{\beta}{4 \tan \theta}\right)$

Where $K_{B}$ is the broadening constant $0.9, \lambda$ is the wavelength of $X$-ray $(\lambda=1.5414 \mathrm{~nm}), \beta$ is full width half maximum (FWHM), $\mathrm{K}_{\mathrm{c}}$ is constant 0.24 . The incorporated $\mathrm{Fe}^{2+}$ ion increases microstrain (190\%) and dislocation density (360\%) in the crystalline plane, and peak broadening were observed causes to decrease in crystallinity and crystallite size (Fig. S1a-d) [28]. The crystallite size was calculated using the scherrer formula from the characteristic peaks of HAp and Fe-HAp which were found to be $11 \pm 1 \mathrm{~nm}$ and $6 \pm 1 \mathrm{~nm}$ respectively. After the adsorption of $\mathrm{As}^{3+}$ ions, the phase purity of HAp-As and Fe-HAp-As was analyzed by XRD. The phase purity of the adsorbent is not affected but the full-width half maximum (FWHM) of HAp-As and Fe-HAp-As reduced compared to before adsorption. Hence, this result indicates the crystallite size has been increased and it was found to be $27 \pm 1 \mathrm{~nm}$ for HAp-As and $18 \pm 1 \mathrm{~nm}$ for Fe-HAp-As (Fig. S1e). In addition, the average crystallinity of HAp and Fe-HAp was increased by adsorption of $\mathrm{As}^{3+}$ ion as shown in Fig. S1f. Accordingly, a drastic reduction were observed in microstrain (61\% for HApAs and $69 \%$ for Fe-HAp-As) and dislocation density of the crystalline lattice (84\% for HAp-As and $90 \%$ for Fe-HAp-As) as shown in Fig. S1g-h. 


\subsection{Fourier transform infrared spectroscopy}

The functional groups of HAp and Fe-HAp are shown in Fig. 2c. The broad absorbance band at $3458 \mathrm{~cm}^{-1}$ and the narrow band at $3792 \mathrm{~cm}^{-1}$ is observed due to the stretching vibration of O-H. The C-O stretching vibrations are observed at $1382 \mathrm{~cm}^{-1}$ and $1460 \mathrm{~cm}^{-1}$ due to the absorption $\mathrm{CO}_{3}{ }^{2-}$ from the atmosphere [34]. The presence of $\mathrm{OH}^{-}$in the HAp lattice was confirmed from the $\mathrm{OH}^{-}$ vibrational band were observed at $1625 \mathrm{~cm}^{-1}$ and $634 \mathrm{~cm}^{-1}$, which are the characteristic vibrations of HAp. The presence of bending vibration of $\mathrm{PO}_{4}{ }^{3-}$ groups are confirmed at $464 \mathrm{~cm}^{-1}$ and $534 \mathrm{~cm}^{-}$

${ }^{1}$. Symmetric and asymmetric stretching vibration of $\mathrm{PO}_{4}{ }^{3-}$ occurred at $957 \mathrm{~cm}^{-1}$ and $1135 \mathrm{~cm}^{-1}$, respectively [40]. The characteristic vibrations of $\mathrm{PO}_{4}{ }^{3-}$ intensities decreased at $534 \mathrm{~cm}^{-1}$ and 634 $\mathrm{cm}^{-1}$, due to the incorporation of $\mathrm{Fe}^{2+}$ ion in HAp (Fig. 2b). Since $400-600 \mathrm{~cm}^{-1}$ is the fingerprint region of the Fe-HAp structure [41-43]. The incorporation of $\mathrm{Fe}^{2+}$ ions into vacant sites of HAp lattice affects the vibrational symmetry leading to the reduction in the intensity of the $\mathrm{PO}_{4}{ }^{3-}$ - group [44]. Accordingly, the FTIR spectra of HAp-As and Fe-HAp-As show the intensity reduction of hydroxyl and carbonate groups as seen in Fig. 2c. Likewise the stretching and bending vibrational mode of $\mathrm{PO}_{4}{ }^{3-}$ band intensity were increased distinctly after the adsorption of $\mathrm{As}^{3+}$ ions due to charge neutralization with $\mathrm{PO}_{4}{ }^{3-}$ site. This neutralization affects the chemical environment of the phosphate ions consequently improving the vibrational symmetry.

\subsection{BET analysis}

The $\mathrm{N}_{2}$ adsorption desorption of HAp and Fe-HAp is shown in Fig. 2d. According to IUPAC classification, the adsorption desorption curve of HAp and Fe-HAp indicates the type IV isotherm [45]. The pore size distribution shows the well-developed cylindrical shape mesoporous structure and the pore size is $15 \pm 0.5 \mathrm{~nm}$ and $9 \pm 0.5 \mathrm{~nm}$ which corresponds to HAp and Fe-HAp. The specific surface area of HAp and Fe-HAp is $39 \pm 1 \mathrm{~m}^{2} / \mathrm{g}$ and $80 \pm 1 \mathrm{~m}^{2} / \mathrm{g}$ respectively is shown in Table S1. The specific surface area of Fe-HAp has increased 105\% due to narrow pores distribution and partial reduction of particle size. Consequently, an increment of specific surface area leads to enhanced $\mathrm{As}^{3+}$ ion adsorption capacity and their affinity [46].

\subsection{TEM and SEM analysis}


The TEM micrograph of synthesized HAp and Fe-HAp adsorbents shows uniform distributions of rod-like morphology as seen in Fig. 3a-b. The dimension of HAp is $220 \pm 5 \mathrm{~nm}$ in length and $45 \pm 5$ $\mathrm{nm}$ in width, whereas Fe-HAp is $55 \pm 3 \mathrm{~nm}$ in length and $20 \pm 3 \mathrm{~nm}$ in width. It was observed that the incorporation of $\mathrm{Fe}^{2+}$ ions in HAp lattice significantly reduces the particle size, which increases the number of active sites and adsorption capacity of $\mathrm{As}^{3+}$. The SEM images of HAp and Fe-HAp nanoparticles are shown in Fig. 3c-d. In the micrograph, uniformly distributed rod-like particles are revealed, the length of HAp was found to be $230 \pm 5 \mathrm{~nm}$ and $52 \pm 5 \mathrm{~nm}$ in width; the length of Fe-HAp was $63 \pm 5 \mathrm{~nm}$ and width was $24 \pm 5 \mathrm{~nm}$, which matched well with the TEM measurements. Similarly, HAp-As and Fe-HAp-As exhibit a uniform distribution of rod-like morphology as shown in Fig. 3e-f. After adsorption, average size of the particles are increased; HAp-As with a length of $250 \pm 3 \mathrm{~nm}$ and width of $58 \pm 3 \mathrm{~nm}$; also the length of Fe-HAp is $70 \pm 3 \mathrm{~nm}$ and width is $30 \pm 3 \mathrm{~nm}$. Elemental analysis of pure and $\mathrm{As}^{3+}$ ion adsorbed HAp and Fe-HAp is shown in Fig. S2a-d. The energy dispersive X-ray (EDX) spectra of HAp shows the presence of Ca, P, O and C elements. In addition, Fe-HAp confirms the presence of $\mathrm{Fe}^{2+}$ ion. Also, the occurrence of the adsorbed $\mathrm{As}^{3+}$ was confirmed in HAp-As and Fe-HAp-As. The Ca/P ratio of HAp and Fe-HAp was 1.65 and 1.64 respectively, whereas the $\mathrm{Ca} / \mathrm{P}$ ratio of HAp-As is 1.52 and Fe-HAp-As is 1.53. Furthermore, the elemental mapping of $\mathrm{As}^{3+}$ ion adsorbed in different $\mathrm{pH}$ values of HAp and FeHAp is shown in Fig. S3. From Fig. S3a shows the uniform distribution of $\mathrm{Ca}, \mathrm{P}, \mathrm{C}$, and $\mathrm{O}$ for HAp and Fe-HAp. In addition, Fe-HAp were shows the uniform distribution of $\mathrm{Fe}^{2+}$ ion also. In $\mathrm{pH} 3$, distribution of $\mathrm{As}^{3+}$ ions is significantly less due to the lower colloidal stability. Whereas, the distribution of $\mathrm{As}^{3+}$ sufficiently improved in the alkaline $\mathrm{pH}$ (Fig. S3b-c). However, the $\mathrm{pH}$ values higher than 9.2 revealed an improper distribution of the $\mathrm{As}^{3+}$ ion by electrostatic repulsion between adsorbent and $\mathrm{As}^{3+}$.

\section{5. pH effects on zeta potential and isoelectric point}

The $\mathrm{pH}$ of the solution plays a crucial role in the adsorption process because it influences the dissociation of adsorbate ion, colloidal stability, and isoelectric point charge $\left(\mathrm{pH}_{\mathrm{pzc}}\right)[9,47]$. Quantification of colloidal stability and $\mathrm{pH}_{\mathrm{pzc}}$ in different $\mathrm{pH}$ values of triple distilled water and $\mathrm{As}^{3+}$ contaminated water are shown in Fig. 4a-b. Generally, Colloidal stability has a significant impact on the adsorption process and it was measured from zeta potential $(\zeta)$. The smaller value of the zeta potential ( $\zeta$ is either positive or negative) indicates the lower colloidal stability whereas 
higher value indicates the higher colloidal stability. At lower colloidal stability, the adsorbent is more prone to change crystal structure and morphology, and increasing aggregation. Whereas, at high colloidal stability, less aggregation takes place, which increases the number of active sites on the adsorbent surface. In triple distilled water at $\mathrm{pH} 3$, HAp exhibited more aggregation or lower colloidal stability, due to lower zeta potential of HAp $(\zeta=-2 \mathrm{mV})$; whereas Fe-HAp showed the incipient stability since the zeta potential value is higher $(\zeta=-15 \mathrm{mV})$. Hence, enhanced colloidal stability of Fe-HAp was observed in a wide range of $\mathrm{pH}$ at 3 to 11 due to the presence of interstitial $\mathrm{Fe}^{2+}$ ion in the HAp lattice. When the solution $\mathrm{pH}$ was increased towards alkaline, the colloidal stability of both the adsorbents significantly improved as seen in Fig. 4a. This improvement leads to the enhanced adsorption affinity and capacity by increasing surface activity. Moreover, the isoelectric point charge (pHpzc) plays an essential role of adsorption by influencing the electrostatic interaction. To analyze the adsorption mechanism, the $\mathrm{pH}_{\mathrm{pzc}}$ was calculated from the $\mathrm{pH}$ drift method[48]. The $\mathrm{pH}_{\mathrm{pzc}}$ of adsorbents HAp and Fe-HAp was measured in triple-distilled water is found to be 7.1 and 7.3, respectively, as shown in Fig. 4b. Adsorbent surface charge was positive at $\mathrm{pH}$ value below $\mathrm{pH}_{\mathrm{pzc}}(7 \pm 0.2)$ due to the complexation of $\mathrm{H}^{+}$ions and the dissolution of phosphate ion from the adsorbent surface. Whereas, the surface charge was negative when the $\mathrm{pH}$ value was higher than the $\mathrm{pH}_{\mathrm{pzc}}$ due to complexation with $\mathrm{OH}^{-}$ions [49].

The colloidal stability and $\mathrm{pH}_{\mathrm{pzc}}$ of the adsorbents were determined from arsenic contaminated water. The colloidal stability of HAp and Fe-HAp improved significantly with an increase in $\mathrm{pH}$ value 3 to 11 and also, the isoelectric point charge of the adsorbents increased from 7.1 to 8.6 for HAp and 7.3 to 9.3 for Fe-HAp. Consequently, this enhancement indicates the $\mathrm{As}^{3+}$ ion complexation on HAp and Fe-HAp adsorbent surface. The $\mathrm{As}^{3+}$ was dissociated in to non-ionic state $\left[\mathrm{H}_{3} \mathrm{AsO}_{3}, \mathrm{As}(\mathrm{OH})_{3}\right]$ at $\mathrm{pH}$ value below 9.2, therefore the adsorption of $\mathrm{As}^{3+}$ on $\mathrm{HAp}$ and FeHAp was enhanced by the surface complexation process. When the $\mathrm{pH}$ value was above $9.2 ; \mathrm{As}^{3+}$ dissociated into anionic states of $\mathrm{As}(\mathrm{OH})^{4-}, \mathrm{AsO}_{2} \mathrm{OH}^{2-}$, and the anionic states were highly repulsed by the negatively charged adsorbent as shown in the schematic representation of Fig. 4c $[6,14,29,49-51]$.

\section{Adsorption}

\subsection{Effect of contact time}


The determination of equilibrium contact time is essential for the adsorption process. Initially, 20 $\mathrm{mL}$ of $1000 \mu \mathrm{g} / \mathrm{L} \mathrm{As}^{3+}$ solution in $\mathrm{pH} 7$ was mixed with $100 \mathrm{mg}$ of HAp and Fe-HAp in different sterilized containers. The mixture of the solution was stirred $(180 \mathrm{rpm})$ at room temperature $\left(25 \pm 1^{\circ} \mathrm{C}\right)$ for different time intervals. The adsorption capacity of $\mathrm{As}^{3+}$ in the various time intervals is calculated and it is shown in Fig. 4d. The whole adsorption process can be divided into two stages as linear and equilibrium of $\mathrm{As}^{3+}$ adsorption. The adsorption capacity was found to increase with contact time and the maximum capacity was achieved at $10 \mathrm{~min}$. After that the adsorption turned sluggish and reached equilibrium. Hence, an equilibrium adsorption time of 10 min was fixed for the subsequent study of $\mathrm{As}^{3+}$ adsorption. Kinetic isotherm was used to understand the adsorption rate and adsorption mechanism of $\mathrm{As}^{3+}$ on the surface of HAp and Fe-HAp.

\subsection{Effect of the initial concentration of $\mathrm{As}^{3+}$}

The maximum adsorption capacity of HAp and Fe-HAp obtained by varying the initial concentration of $\mathrm{As}^{3+}$ ion $(100 \mu \mathrm{g} / \mathrm{L}-1000 \mu \mathrm{g} / \mathrm{L})$ is shown in Fig. 4e. $100 \mathrm{mg}$ of HAp and FeHAp were taken into different sterilized containers with various initial concentrations of $\mathrm{As}^{3+}$ solution ( $\mathrm{pH} 7)$, at room temperature $\left(25 \pm 1^{\circ} \mathrm{C}\right)$. The contact time was fixed at the equilibrium time (10 $\mathrm{min}$ ), and the shaking speed was set to be $180 \mathrm{rpm}$. The removal capacity of both adsorbents improved with the increasing initial concentration of $\mathrm{As}^{3+}$. This indicates that the higher initial concentration of $\mathrm{As}^{3+}$ enhanced adsorbate mobility, driving force and reduced mass transfer resistance between adsorbate and adsorbent [52]. The adsorption of $\mathrm{As}^{3+}$ were increased up to a concentration of $500 \mu \mathrm{g} / \mathrm{L}$ thereafter, adsorption was attain equilibrium. The equilibrium adsorption capacity of $\mathrm{As}^{3+}$ on HAp and Fe-HAp was found to be $139 \mu \mathrm{g} / \mathrm{g}$ and $183 \mu \mathrm{g} / \mathrm{g}$, respectively.

\subsection{Adsorption isotherm}

\subsubsection{Kinetic isotherm}

The experimental kinetic data was fitted to two different isotherms, such as Lagergren pseudo-first and Lagergren pseudo-second-order kinetics [53]. The first and second-order kinetics reveal the physisorption and chemisorption, respectively. The linear fit expression of first and second-order kinetics is given in Eqs. (6-7). 


$$
\begin{aligned}
& \log \left(Q_{e}-Q_{t}\right)=\log \left(Q_{e}\right)-\left(\frac{K_{1}}{2.303}\right) t \\
& \frac{t}{Q_{t}}=\frac{1}{\left(K_{2} \times Q e^{2}\right)}+\left(\frac{1}{Q_{t}}\right) t
\end{aligned}
$$

Where $Q_{t}$ and $Q_{e}$ represent the given time and equilibrium adsorption capacity $(\mu \mathrm{g} / \mathrm{g})$, respectively. $\mathrm{K}_{1}$ is the first-order rate constant $\left(\mathrm{min}^{-1}\right)$. The values of $\mathrm{Q}_{e}$ and $\mathrm{K}_{1}$ were determined from intercept and slope in the linear fit of $\log \left(\mathrm{Q}_{\mathrm{e}}-\mathrm{Q}_{\mathrm{t}}\right)$ as a function of time $\mathrm{t}$, as shown in Fig. 5a. $\mathrm{K}_{2}$ is the second-order rate constant $\left(\mathrm{g} / \mu \mathrm{g} \mathrm{min}{ }^{-1}\right)$. The values of $\mathrm{K}_{2}$ and $\mathrm{Q}_{\mathrm{e}}$ were calculated from the intercept and slope in a linear plot of $1 / Q_{t}$ as a function of time $t$, as shown in Fig. 5b $[54,55]$.

\subsubsection{Intra-particle diffusion}

The intra-particle diffusion isotherm was used to find the rate-controlling mechanism of $\mathrm{As}^{3+}$ diffusion on HAp and Fe-HAp during the adsorption [5]. The linear expression of the intra-particle diffusion is given in Eq. (8).

$Q_{t}=K_{i} \sqrt{t}+C_{i}$

Where $\mathrm{K}_{\mathrm{i}}$ is the intra-particle diffusion rate constant $\left(\mu \mathrm{g} / \mathrm{g} \mathrm{min}^{-1 / 2}\right)$ and $\mathrm{C}_{\mathrm{i}}$ is the boundary layer thickness of $\mathrm{As}^{3+}$ adsorption. Further, $\mathrm{K}_{\mathrm{i}}$ and $\mathrm{C}_{\mathrm{i}}$ can be calculated from the slope and intercept of intra-particle diffusion linear fit of $Q_{t}$ as a function of $ل_{t}$ is shown in Fig. 5c [56].

The linear regression of $\mathrm{R}^{2}$ is well matched in second-order kinetics compared to first-order kinetics. Also, the adsorption capacities of theoretical and experimental values are in good agreement with second-order kinetics. Hence, it confirms the chemisorption of $\mathrm{As}^{3+}$ on HAp and Fe-HAp. The second-order rate constant $\left(\mathrm{K}_{2}\right)$ indicates that the adsorption rate $(1 \mathrm{~min})$ and their capacity $\left(\mathrm{Q}_{\mathrm{e}}=538 \%\right)$ are higher for Fe-HAp when compared to HAp nanoparticles (Table 1). The $\mathrm{As}^{3+}$ adsorption on HAp and Fe-HAp shows the two-stage adsorption process. Initially, the linear portion revealed the adsorption of $\mathrm{As}^{3+}$ as a combination of surface and pore diffusion process. The last linear part represents the equilibrium adsorption as shown in Fig. 5c.

\subsubsection{Langmuir, Freundlich, and DKR isotherm}


The equilibrium adsorption of $\mathrm{As}^{3+}$ is either monolayer or multilayer distribution, which is determined from Langmuir and Freundlich isotherm, respectively. In monolayer adsorption, active sites on the adsorbent surface are distinct and identical to each other [57,58]. The linear expression of Langmuir isotherm is given by Eq. (9).

$\frac{C_{e}}{Q_{e}}=\frac{1}{Q m K_{L}}+\frac{C_{e}}{Q_{m}}$

Where $C_{e}$ represents the equilibrium concentration $(\mu \mathrm{g} / \mathrm{L}), \mathrm{K}_{\mathrm{L}}$ is Langmuir isotherm constant $(\mathrm{L} / \mu \mathrm{g})$, suggesting the adsorption affinity (or) sensitivity, and $\mathrm{Q}_{\mathrm{m}}$ is theoretical monolayer adsorption capacity $(\mu \mathrm{g} / \mathrm{g})$. The values of $\mathrm{Q}_{\mathrm{m}}$ and $\mathrm{K}_{\mathrm{L}}$ are calculated from the intercept and slope in a linear fit of $1 / \mathrm{C}_{\mathrm{e}}$ vs. $1 / \mathrm{Q}_{\mathrm{e}}$ as shown in Fig. 5d. The essential feature of Langmuir is a dimensionless constant called the separation factor $\left(R_{L}\right)$, which is given as Eq. (10). The value of the $R_{L}$ indicates the various types of adsorption, such as linear $(R L=1)$, unfavorable $(R L>1)$, favorable $(0<\mathrm{RL}>1)$ and irreversible $(\mathrm{RL}=0)$ [59]. Freundlich isotherm explains multilayer adsorption on heterogeneous surfaces and it gives the empirical relationship between the adsorbate and adsorbent, the linear expression of Freundlich isotherm is given by Eq. (11) [47,60]. $R_{L}=\frac{1}{\left(1+K_{L} C_{o}\right)}$

$\log \mathrm{Q}_{\mathrm{e}}=\log \mathrm{K}_{\mathrm{F}}+\left(\frac{1}{n}\right) \log \mathrm{C}_{\mathrm{e}}$

Where $K_{F}$ is the adsorption capacity $(\mu \mathrm{g} / \mathrm{g}$ ) of Freundlich isotherm and $1 / \mathrm{n}$ is the Freundlich exponent. The values of $\mathrm{K}_{\mathrm{F}}$ and $1 / \mathrm{n}$ are determined from the intercept and slope of the linear fit of $\log$ Ce vs. $\log Q_{e}$ as shown in Fig. 5e. The value of $1 / n$ indicate the adsorption behavior as it is linear $[(1 / n)=1]$ or unfavorable $[(1 / n)>1]$ or favorable $[0.1<(1 / n)>1]$ or irreversible $[(1 / n)=0]$.

The Dubinin-Radushkevich isotherm is generally applied to distinguish between physisorption and chemisorption based on the Gaussian energy distribution. The physisorption process occurs when the atom/molecule is adsorbed by Van der Waals force of the material, whereas chemisorption occurs either by valance electron sharing or ion exchange between adsorbate and adsorbent [61-63]. The linear expression of Dubinin-Radushkevich isotherm is given in Eq. (12). 
$\ln Q_{e}=\ln Q m-\beta \varepsilon^{2}$

$\varepsilon=R T \ln \left(1+\frac{1}{C_{e}}\right)$

Where $\beta$ is DKR constant; it gives adsorption mean energy $(\mathrm{mol} / \mathrm{J})^{2}$. $\varepsilon$ is Polanyi potential expressed in Eq. (13); $Q_{m}$ is maximum adsorption capacity $(\mu \mathrm{g} / \mathrm{g}), \mathrm{R}$ is the universal gas constant $8.314(\mathrm{~J} / \mathrm{mol} \mathrm{K})$, and $\mathrm{T}$ is the absolute temperature $(\mathrm{K})$. The $\beta$ and $\mathrm{Q}_{\mathrm{m}}$ can be calculated from the slope and intercept of the $\ln Q_{\mathrm{e}}$ vs. $\varepsilon^{2}$ linear fit, as shown in Fig. 5f. The adsorption is divided into three types based on the value of Gaussian energy (E) distribution as given in Eq. (14). They are physisorption ( $\mathrm{E}<8 \mathrm{~kJ} / \mathrm{mol})$, chemical ion exchange $(8 \mathrm{~kJ} /$ mole $\leq \mathrm{E} \leq 16 \mathrm{~kJ} / \mathrm{mole})$, and strong chemisorption than ion exchange $(\mathrm{E}>16 \mathrm{~kJ} / \mathrm{mol})$ [64]. The adsorption of $\mathrm{As}^{3+}$ will follow any one of the above-mentioned adsorption processes.

$$
E=\frac{1}{\sqrt{-2 \beta}}
$$

The linear fit of Langmuir, Freundlich and DKR isotherms is shown in Fig. 5d-f. The linear regression $\mathrm{R}^{2}$ values are well-matched with the Langmuir isotherm when compared to the Freundlich and DKR isotherms. Also, the experimental and theoretical values of the $\mathrm{As}^{3+}$ adsorption capacity are better suited for Langmuir and DKR isotherm than the Freundlich isotherm. Moreover, separation factor RL indicates that the adsorption favored Langmuir isotherm, hence the adsorption of $\mathrm{As}^{3+}$ is monolayer was confirmed. The maximum adsorption capacity of $\mathrm{As}^{3+}$ on HAp and Fe-HAp is $139 \mu \mathrm{g} / \mathrm{g}$ and $183 \mu \mathrm{g} / \mathrm{g}$, respectively. The $\mathrm{As}^{3+}$ adsorption affinity or sensitivity found to be $3.85 \mu \mathrm{g} / \mathrm{L}$ for HAp and $0.71 \mu \mathrm{g} / \mathrm{L}$ for Fe-HAp (shown in Table 1). The adsorption affinity of Fe-HAp was enhanced at the trace level $(\leq 50 \mu \mathrm{g} / \mathrm{L})$, which is $83-99.9 \%$ higher than the previous reports as so far shown in Table 2. The Gaussian energy distribution on HAp and Fe-HAp is $18.6 \mathrm{~kJ} / \mathrm{mol}$ and $21.3 \mathrm{~kJ} / \mathrm{mol}$, respectively and these results suggest stronger chemical adsorption than ion-exchange process.

\section{Quantification of $\mathrm{Fe}^{2+}$ ion release test}

Fig. S4. shows the quantification of $\mathrm{Fe}^{2+}$ ion in HAp nanoparticle (Sample C) and also $\mathrm{Fe}^{2+}$ leached from $\mathrm{As}^{3+}$ contaminated water (Sample B), and triple distilled water (Sample A). The concentration of $\mathrm{Fe}^{2+}$ ion on Fe-HAp was estimated to be $5.06 \pm 0.05 \mathrm{mg} / \mathrm{g}$. The concentration of 
$\mathrm{Fe}^{2+}$ ion released in triple-distilled water and $\mathrm{As}^{3+}$ contaminated water was found to be $0.005 \pm$ $0.001 \mathrm{mg} / \mathrm{L}$ and $0.019 \pm 0.001 \mu \mathrm{g} / \mathrm{L}$ respectively, which is 600 times below the acceptable level of iron in drinking water (1-3 mg/L) [65]. In a very low quantity of iron incorporation, it leads to highly efficient adsorption of $\mathrm{As}^{3+}$ and also confirms the insignificant release of iron during the adsorption process.

\section{Conclusion}

The HAp and Fe-HAp nanorods were synthesized via a simple and cost-effective hydrothermal method for the removal of $\mathrm{As}^{3+}$ ion. Merely $0.5 \mathrm{wt} \%$ of $\mathrm{Fe}^{2+}$ ion is incorporated in the HAp which results in enhanced physiochemical properties of the adsorbent and improves adsorption of $\mathrm{As}^{3+}$. Remarkably, the $\mathrm{Fe}^{2+}$ ion improves the HAp colloidal stability, particle size (Drastic reduction of $400 \%$ in length and $225 \%$ in width), and specific surface area (105\% higher than the HAp). As a result, more active sites are formed in Fe-HAp than HAp which leads to obtaining a maximum adsorption capacity of $\mathrm{As}^{3+}$. It was found to be a maximum adsorption capacity of $\mathrm{As}^{3+}$ is $183 \mu \mathrm{g} / \mathrm{g}$ with a higher adsorption rate $(538 \%)$ at trace level contamination $(\leq 50 \mu \mathrm{g} / \mathrm{L})$. In addition, the dopant $\mathrm{Fe}^{2+}$ ion ensures the higher adsorption affinity (83-99.9\%) compared to previously reported literature so far. The adsorption of $\mathrm{As}^{3+}$ ion, could not change the hydroxyapatite phase and morphology of adsorbent. From isotherm theoretical evaluation, the adsorption of the $\mathrm{As}^{3+}$ ion confirmed to be monolayer chemisorption rather than the ion-exchange process. Furthermore, quantification of iron studies showed a very lower concentration $(0.005$ to $0.019 \mathrm{mg} / \mathrm{L})$ of $\mathrm{Fe}^{2+}$ ion was leaked during the adsorption process which was 600 times lower than the WHO toxic limits of iron in water. Hence, the Fe-HAp is a cost-effective, potential adsorbent, and promising for removal of highly toxic $\mathrm{As}^{3+}$ even at trace level $(\leq 50 \mu \mathrm{g} / \mathrm{L})$ and maintaining water quality.

\section{Acknowledgements}

The authors would like to thank the government of India for the financial support from the Department of Science And Technology through the scheme of Technology Development Programme -1010 [No: DST/TM/WTI/2K16/219(G)-A]. One of the authors (Narayana Kalkura Subbaraya) thanks the University Grants Commission, India for the award of the Basic Scientific Research (UGC-BSR) Faculty Fellowship [No. F.4-5(11)2019 (BSR)]. 


\section{Credit authorship contribution statement}

Sandeep Eswaran Panchu: Conceptualization, Methodology, Writing - Original Draft. Saranya Sekar: Validation, Investigation. Vani Rajaram: Writing - Review \& Editing. Elayaraja Kolanthai: Writing - Review \& Editing. Sarojini Jeeva Panchu: Formal analysis, Writing - Review \& Editing. Hendrik C.Swart: Writing - Review \& Editing. Narayana Kalkura Subbaraya: Writing - Review \& Editing, Supervision, Investigation, Project administration

\section{Declaration of competing interests}

The authors declare that they have no known competing financial interests or personal relationships that could have appeared to influence the work reported in this paper. This article is original and new, has been written by the stated authors who are all aware of its content and approve its submission, has not been published previously, it is not under consideration for publication elsewhere, no conflict of interest exists. The article will not be published elsewhere in the same form, in any language, without the written consent of the publisher

\section{Reference}

1. D. E. Baker and L. Chesnin, Adv. Agron. 27, 305 (1975).

2. D. Mohan and C. U. Pittman, J. Hazard. Mater. 142, 1 (2007).

3. W. Jiang, X. Chen, Y. Niu, and B. Pan, J. Hazard. Mater. 243, 319 (2012).

4. T. K. Das, T. S. Sakthivel, A. Jeyaranjan, S. Seal, and A. N. Bezbaruah, Chemosphere 253, $126702(2020)$.

5. X. Min, C. Zhou, C. Han, J. Tang, D. Liu, and Y. Luo, J. Mater. Sci. 55, 8145 (2020).

6. V. M. Boddu, K. Abburi, J. L. Talbott, E. D. Smith, and R. Haasch, Water Res. 42, 633 (2008).

7. I. Andjelkovic, D. Stankovic, J. Nesic, J. Krstic, P. Vulic, D. Manojlovic, and G. Roglic, Ind. Eng. Chem. Res. 53, 10841 (2014). 
8. S. Yao, Z. Liu, and Z. Shi, J. Environ. Heal. Sci. Eng. 12, 6 (2014).

9. L. L. Min, L. Bin Zhong, Y. M. Zheng, Q. Liu, Z. H. Yuan, and L. M. Yang, Sci. Rep. 6, (2016).

10. C. K. Jain and I. Ali, Water Res. 34, 4304 (2000).

11. M. Khatamian, N. Khodakarampoor, and M. Saket-Oskoui, J. Colloid Interface Sci. 498, 433 (2017).

12. P. Mondal, C. B. Majumder, and B. Mohanty, J. Hazard. Mater. 137, 464 (2006).

13. L. H. Velazquez-Jimenez, J. A. Arcibar-Orozco, and J. R. Rangel-Mendez, J. Environ. Manage. 212, 121 (2018).

14. N. Zhu, J. Qiao, Y. Ye, and T. Yan, J. Environ. Manage. 211, 73 (2018).

15. P. Sabbatini, F. Yrazu, F. Rossi, G. Thern, A. Marajofsky, and M. M. Fidalgo de Cortalezzi, Water Res. 44, 5702 (2010).

16. H. Chen, J. Li, X. Wu, and X. Wang, Ind. Eng. Chem. Res. 53, 16051 (2014).

17. C. S. Fan, S. C. Tseng, K. C. Li, and C. H. Hou, J. Hazard. Mater. 312, 208 (2016).

18. M. G. Mostafa, Y. H. Chen, J. S. Jean, C. C. Liu, and H. Teng, Water Sci. Technol. 62, 378 (2010).

19. X. Gao, Y. Peng, L. Guo, Q. Wang, C. Y. Guan, F. Yang, and Q. Chen, J. Environ. Manage. 271, 111045 (2020).

20. T. Türk and I. Alp, J. Ind. Eng. Chem. 20, 732 (2014).

21. T. S. Singh and K. K. Pant, Sep. Purif. Technol. 36, 139 (2004).

22. R. C. Vaishya and S. K. Gupta, J. Chem. Technol. Biotechnol. 78, 73 (2003).

23. J. Kamieniak, P. J. Kelly, C. E. Banks, and A. M. Doyle, J. Inorg. Organomet. Polym. Mater. 
28, 84 (2018).

24. H. L. Lien and R. T. Wilkin, Chemosphere 59, 377 (2005).

25. X. H. Guan, J. Wang, and C. C. Chusuei, J. Hazard. Mater. 156, 178 (2008).

26. A. Masoumi, M. Ghaemy, and A. N. Bakht, Ind. Eng. Chem. Res. 53, 8188 (2014).

27. D. Dickson, G. Liu, and Y. Cai, J. Environ. Manage. 186, 261 (2017).

28. D. F. Mercado, G. Magnacca, M. Malandrino, A. Rubert, E. Montoneri, L. Celi, A. Bianco Prevot, and M. C. Gonzalez, ACS Appl. Mater. Interfaces 6, 3937 (2014).

29. A. F. D. de Namor, N. Al Hakawati, W. A. Hamdan, R. Soualhi, S. Korfali, and L. Valiente, J. Hazard. Mater. 326, 61 (2017).

30. N. Kataria and V. K. Garg, Chemosphere. 208, 818-828 (2018).

31. B. Hu, L. Wu, M. Ou, X. Wang, and Y. Tang, J. Inorg. Organomet. Polym. Mater. 31, 2627 (2021).

32. M. Ashok, N. Meenakshi Sundaram, and S. Narayana Kalkura, Mater. Lett. 57, 2066 (2003).

33. E. Kolanthai, K. Ganesan, M. Epple, and S. N. Kalkura, Mater. Today Commun. 8, 31 (2016).

34. V. Sarath Chandra, G. Baskar, R. V. Suganthi, K. Elayaraja, M. I. Ahymah Joshy, W. Sofi Beaula, R. Mythili, G. Venkatraman, and S. Narayana Kalkura, ACS Appl. Mater. Interfaces 4, 1200 (2012).

35. K. Lin, J. Chang, X. Liu, L. Chen, and Y. Zhou, CrystEngComm 13, 4850 (2011).

36. M. Okada and T. Matsumoto, Jpn. Dent. Sci. Rev. 51, 85 (2015).

37. Z. Y. Li, W. M. Lam, C. Yang, B. Xu, G. X. Ni, S. A. Abbah, K. M. C. Cheung, K. D. K. Luk, and W. W. Lu, Biomaterials 28, 1452 (2007). 
38. V. Mote, Y. Purushotham, and B. Dole, J. Theor. Appl. Phys. 6, 2 (2012).

39. H. Kamal and A. M. Hezma, PSIJ. 7(3). 137-151 (2015)

40. A. Destainville, E. Champion, D. Bernache-Assollant, and E. Laborde, Mater. Chem. Phys. 80, 269 (2003).

41. Y. S. Li, J. S. Church, and A. L. Woodhead, J. Magn. Magn. Mater. 324, 1543 (2012).

42. O. Kaygili, S. V. Dorozhkin, T. Ates, A. A. Al-Ghamdi, and F. Yakuphanoglu, Ceram. Int. 40, 9395 (2014).

43. J. Trinkunaite-Felsen, A. Prichodko, M. Semasko, R. Skaudzius, A. Beganskiene, and A. Kareiva, Adv. Powder Technol. 26, 1287 (2015).

44. H. Shi, F. He, and J. Ye, J. Mater. Chem. B 4, 1712 (2016).

45. Z. A. Alothman, Materials (Basel). 5, 2874 (2012).

46. C. Zhang, W. Wang, A. Duan, G. Zeng, D. Huang, C. Lai, X. Tan, M. Cheng, R. Wang, C. Zhou, W. Xiong, and Y. Yang, Chemosphere 222, 184 (2019).

47. M. A. Espinoza-Sánchez, K. Arévalo-Niño, I. Quintero-Zapata, I. Castro-González, and V. Almaguer-Cantú, J. Environ. Manage. 251, 109595 (2019).

48. S. Haq, W. Rehman, and M. Waseem, J. Inorg. Organomet. Polym. Mater. 29, 651 (2019).

49. A. I. A. Sherlala, A. A. A. Raman, M. M. Bello, and A. Buthiyappan, J. Environ. Manage. 246, 547 (2019).

50. X. J. Gong, Y. S. Li, Y. Q. Dong, and W. G. Li, Chemosphere 250, 126275 (2020).

51. A. Nakarmi, S. E. Bourdo, L. Ruhl, S. Kanel, M. Nadagouda, P. Kumar Alla, I. Pavel, and T. Viswanathan, J. Environ. Manage. 272, 111048 (2020).

52. R. Bardestani, C. Roy, and S. Kaliaguine, J. Environ. Manage. 240, 404 (2019). 
53. Z. Liu, X. He, X. Yang, H. Ding, D. Wang, D. Ma, and Q. Feng, J. Mater. Sci. 56, 11248 (2021).

54. B. Nayak, A. Samant, R. Patel, and P. K. Misra, ACS Omega 2, 8118 (2017).

55. A. A. Ali, I. S. Ahmed, and E. M. Elfiky, J. Inorg. Organomet. Polym. Mater. 31, 384 (2021).

56. J. Zhang, X. Ma, L. Yuan, and D. Zhou, J. Environ. Manage. 256, 109959 (2020).

57. Y. Su, J. Mater. Sci. 53, 4078 (2018).

58. M. Rabiee Faradonbeh, A. A. Dadkhah, A. Rashidi, S. Tasharofi, and F. Mansourkhani, J. Inorg. Organomet. Polym. Mater. 28, 829 (2018).

59. B. Zhang, T. Zhang, Z. Zhang, and M. Xie, J. Mater. Sci. 54, 11037 (2019).

60. T. Ma, Y. Wu, N. Liu, and Y. Wu, J. Inorg. Organomet. Polym. Mater. 30, 4027 (2020).

61. A. Dạbrowski, Adv. Colloid Interface Sci. 93, 135 (2001).

62. K. Vijayaraghavan, T. V. N. Padmesh, K. Palanivelu, and M. Velan, J. Hazard. Mater. 133, 304 (2006).

63. K. Y. Foo and B. H. Hameed, Chem. Eng. J. 156, 2 (2010).

64. N. D. Hutson and R. T. Yang, Adsorption 3, 189 (1997).

65. World Health Organization, Who/Sde/Wsh/03.04/08 2, 4 (2003). 


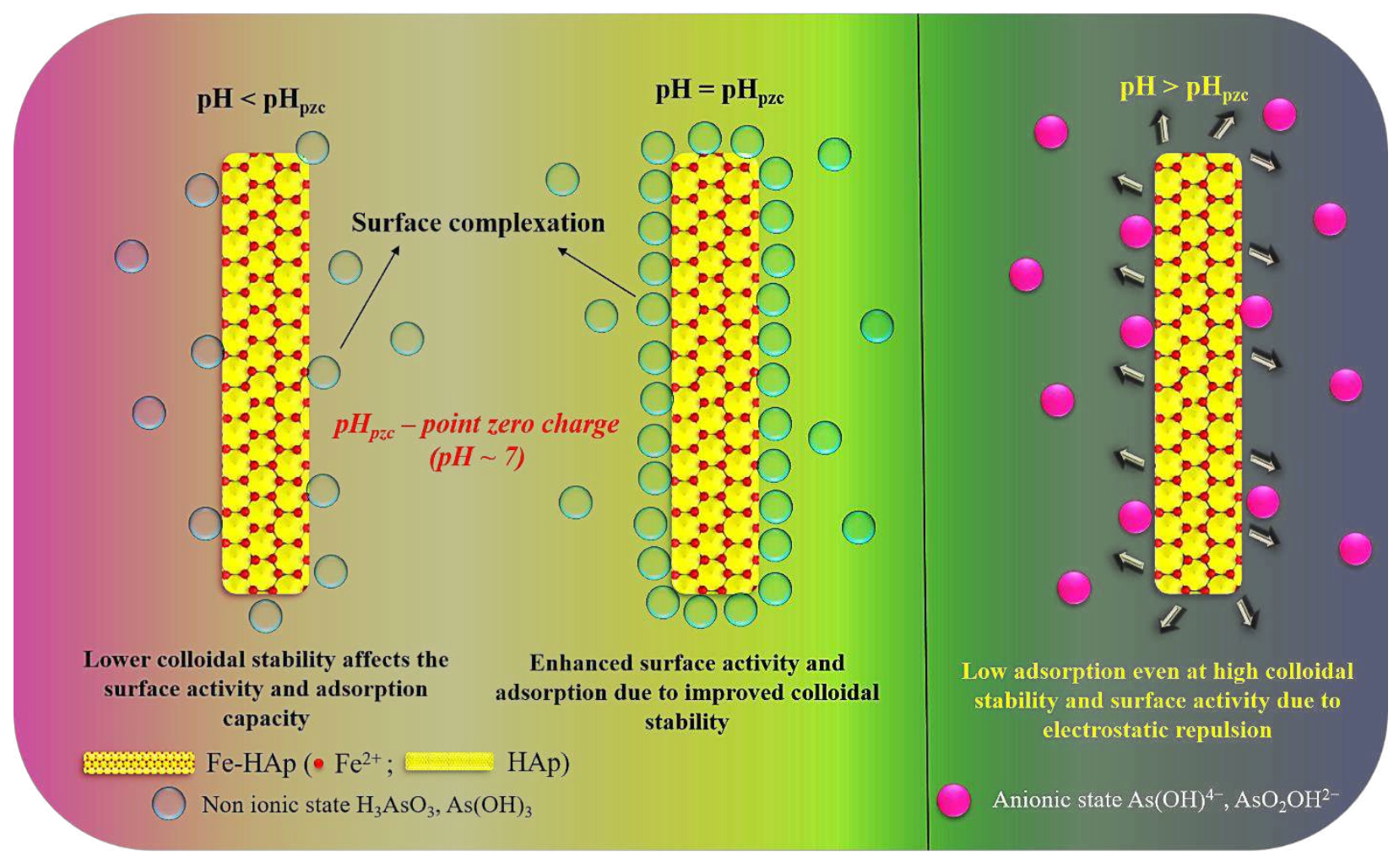

\section{Graphical abstract}




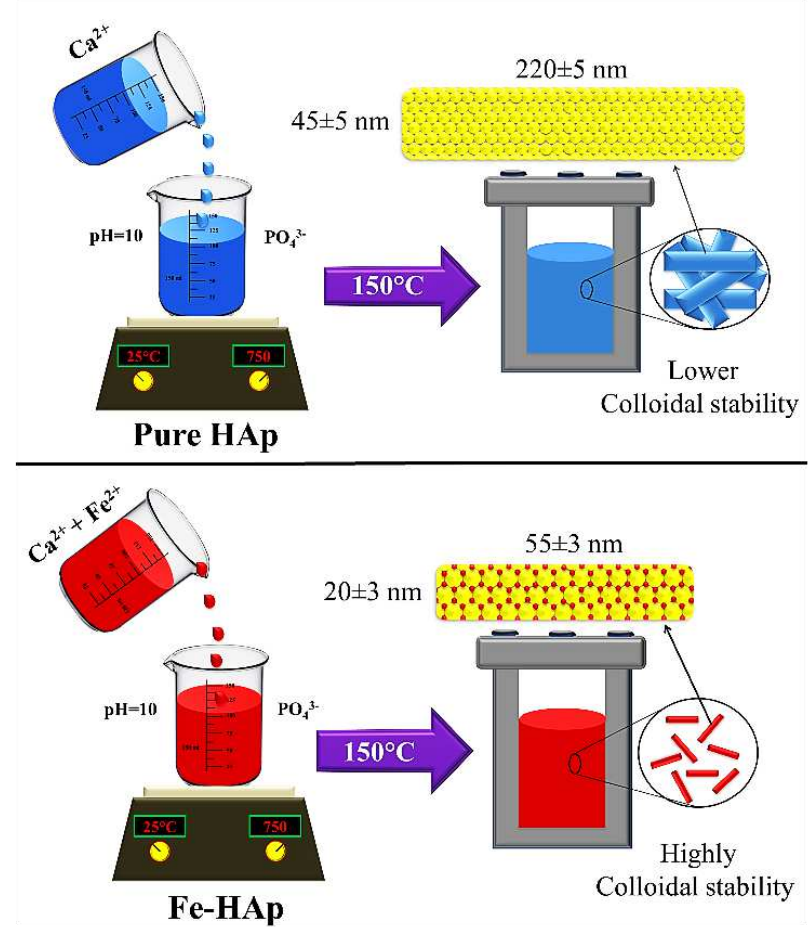

Fig. 1 Schematic representation of tailoring ability of incorporated $\mathrm{Fe}^{2+}$ ion and enhances physicochemical properties of the adsorbent 

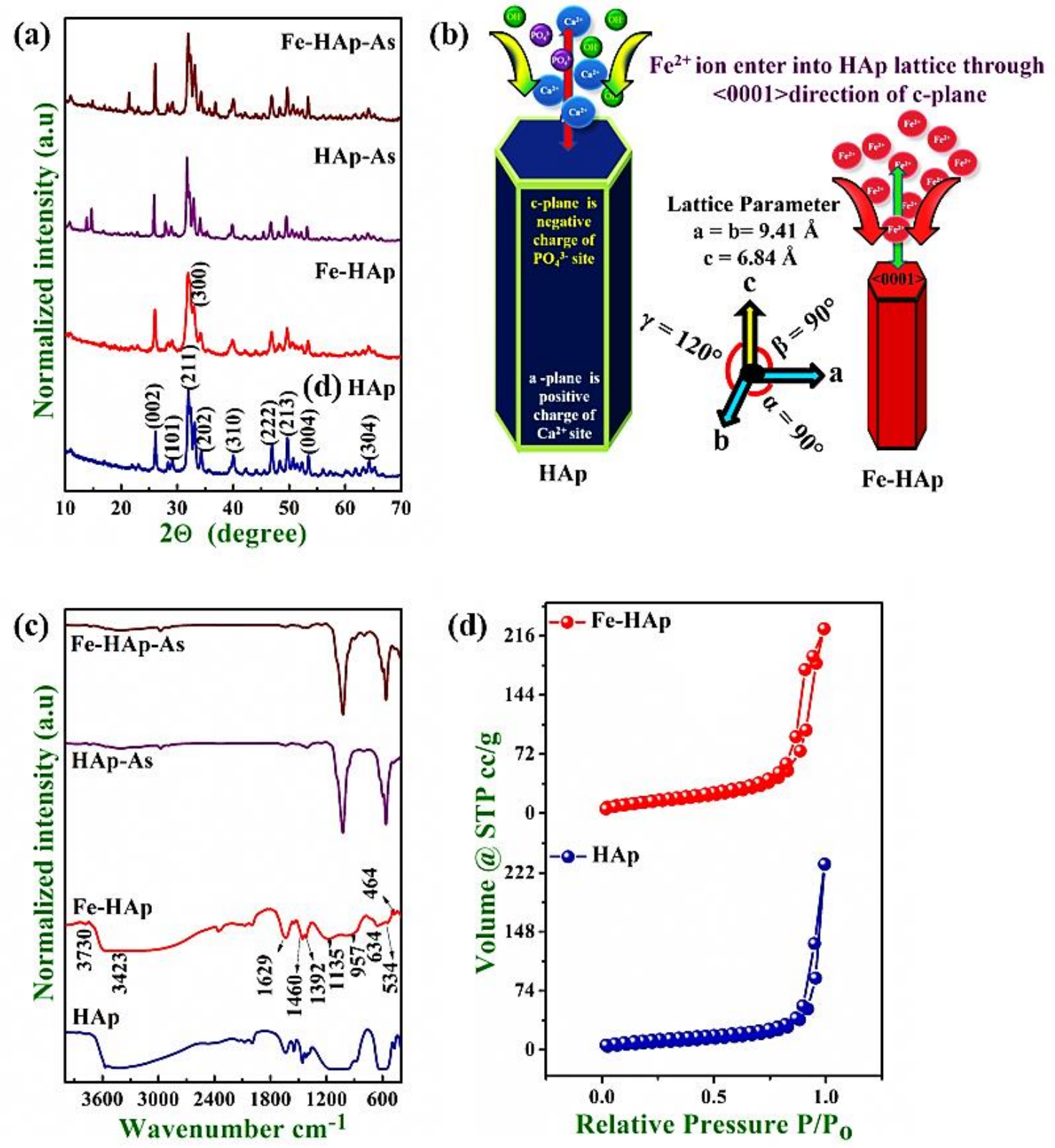

Fig. 2 (a) XRD pattern of synthesized and $\mathrm{As}^{3+}$ ion adsorbed HAp and Fe-HAp, (b) Schematic representation of growth of $\mathrm{HAp}$ nano-rod and $\mathrm{Fe}^{2+}$ ion affect the negative charge of $\mathrm{PO}_{4}{ }^{3-}$ sites in <0001> direction of c-axis, (c) FT-IR Spectra of before and after As ${ }^{3+}$ ion adsorbed HAp and Fe-HAp, and (d) $\mathrm{N}_{2}$ adsorption-desorption plot of HAp and Fe-HAp 

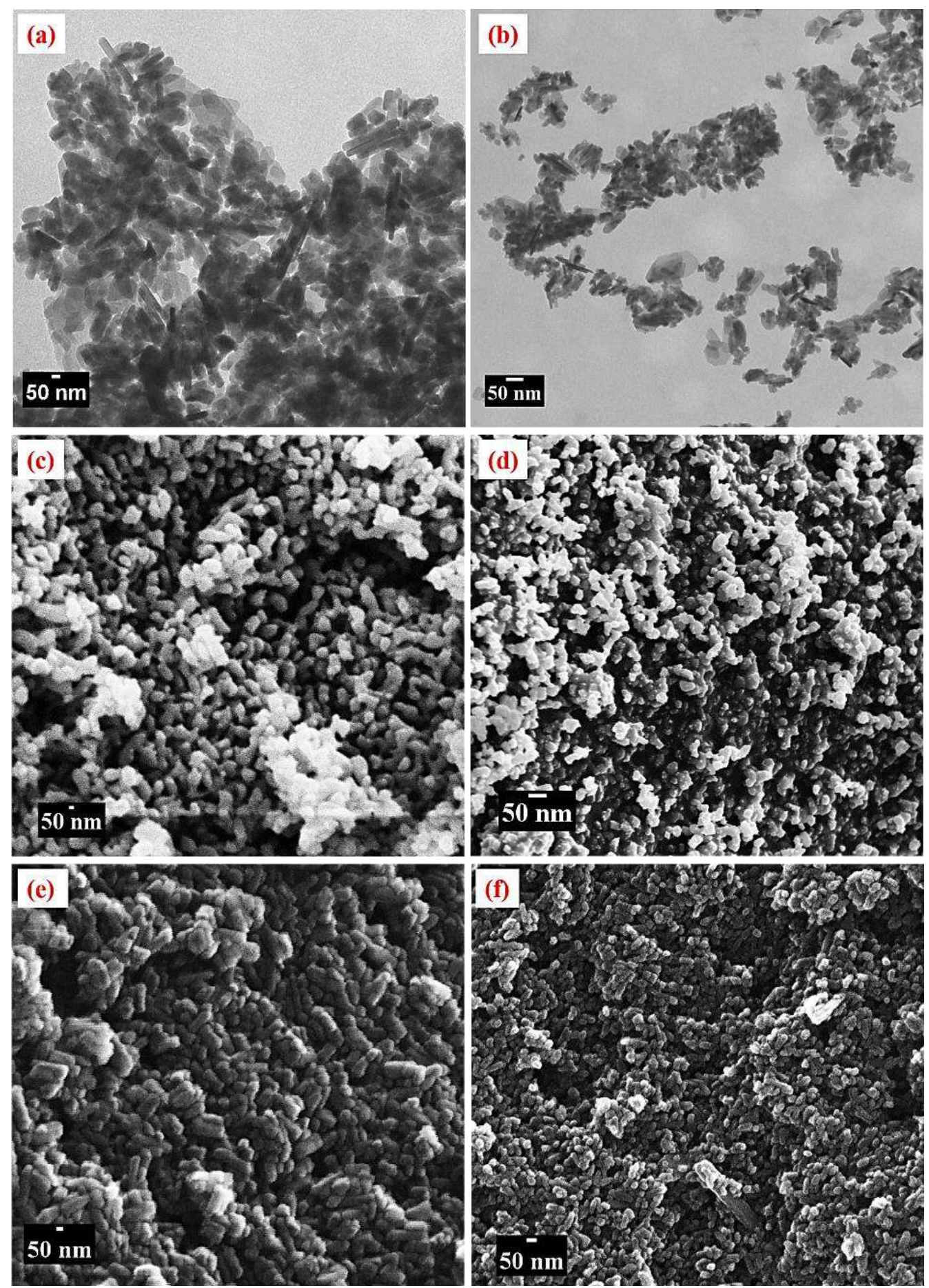

Fig. 3 (a-b) TEM micrograph of synthesized HAp and Fe-HAp, (c-d) SEM micrograph of HAp and Fe-HAp, and (e-f) SEM micrograph of $\mathrm{As}^{3+}$ ion adsorbed HAp (HAp-As) and Fe-HAp (Fe-HAp-As) 
(a)

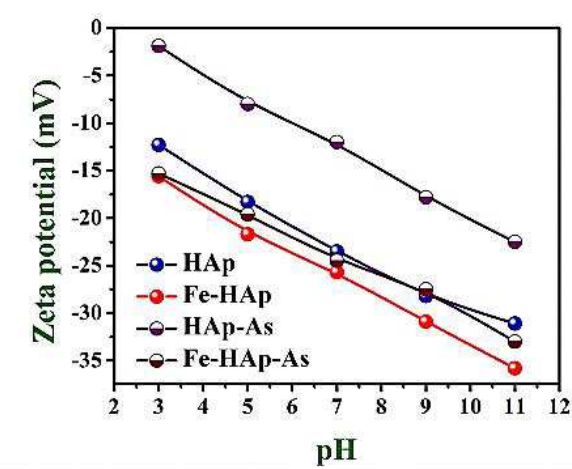

(c)
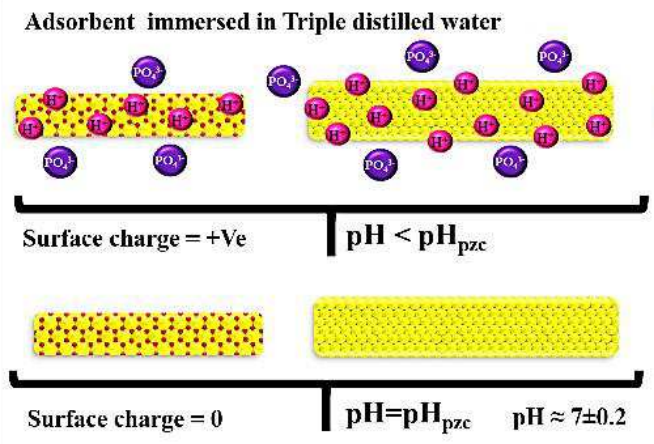

(b)

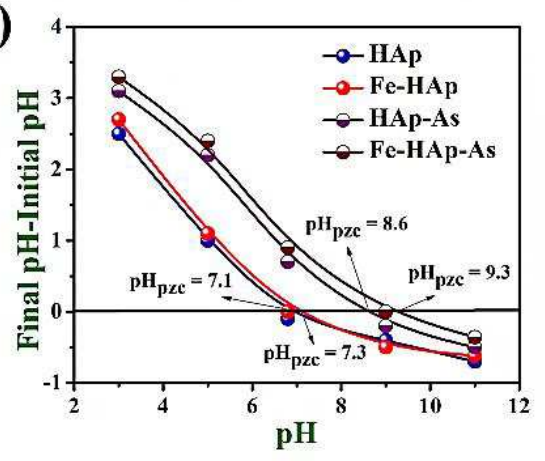

Adsorbent immersed in arsenite contaminated water
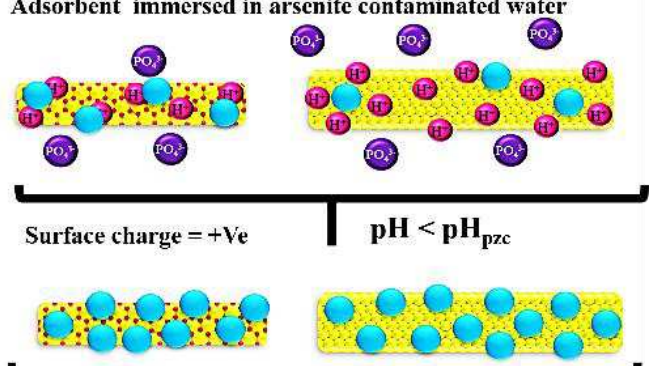

Surface charge $=0$
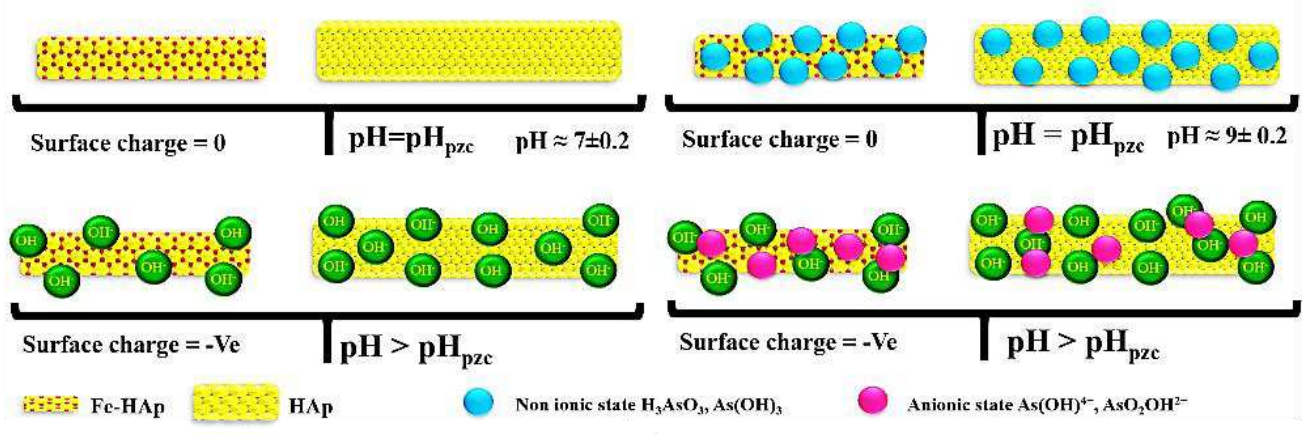

(d)

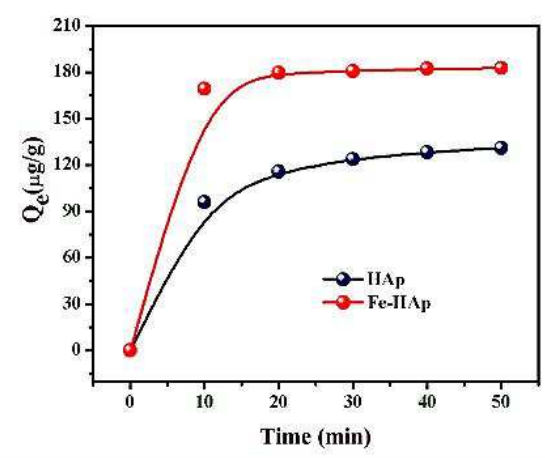

Fig. 4 Effect of pH on HAp and Fe-HAp in deionized water and $\mathrm{As}^{3+}$ ion contaminated water: (a) Zeta potential, (b) Point zero charge (c) Schematic representation of $\mathrm{pH}$ affect the zero pint charge of before and after adsorption of $\mathrm{As}^{3+}$ ion, (d) Effect of contact time [pH=7; concentration $=1000 \mu \mathrm{g} / \mathrm{L}$; Dosage $=100 \mathrm{mg} ; \mathrm{rpm}=180$ and temperature $=298 \mathrm{~K}$, and (e) Effect of initial concentration of $\mathrm{As}^{3+}[\mathrm{pH}=7$; Time $=10 \mathrm{~min}$; Dosage $=100 \mathrm{mg} ; \mathrm{rpm}=180$ and temperature $=298 \mathrm{~K}]$ 
(a)

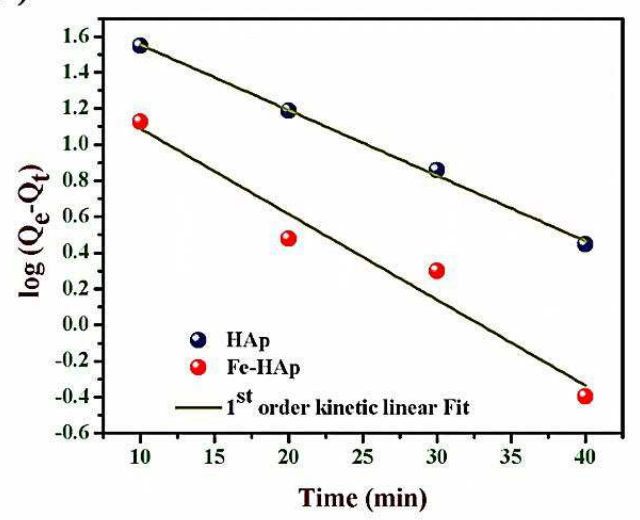

(c)

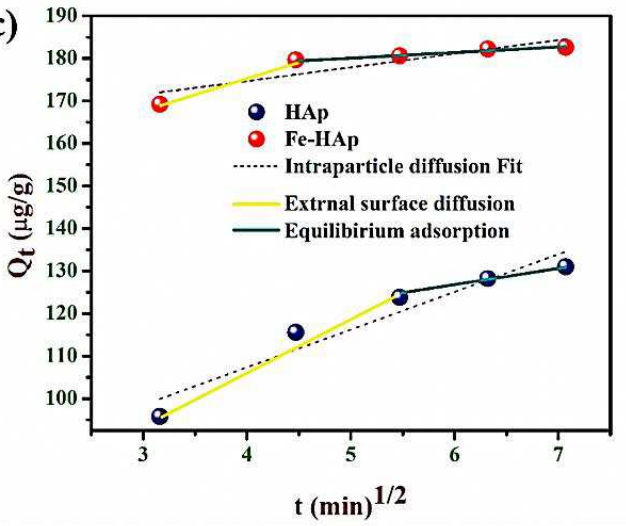

(e)

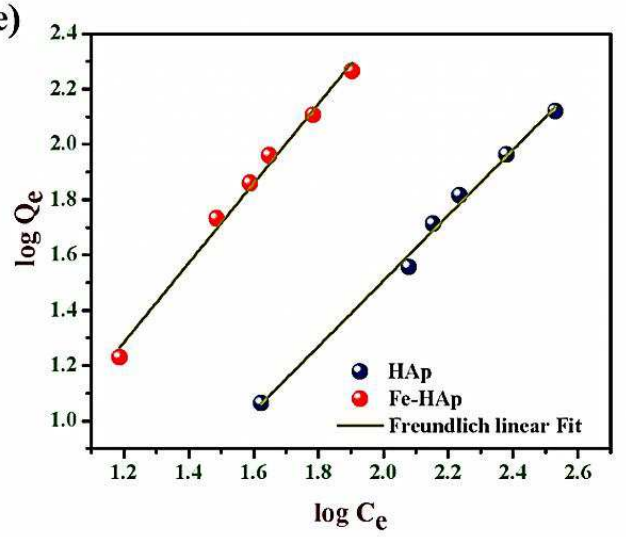

(b)

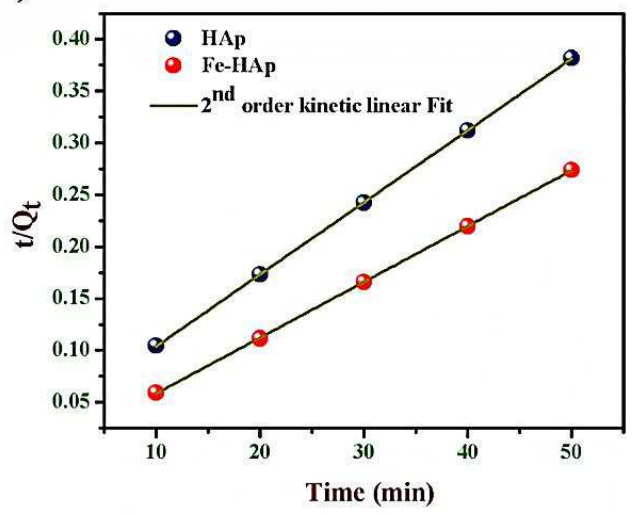

(d)

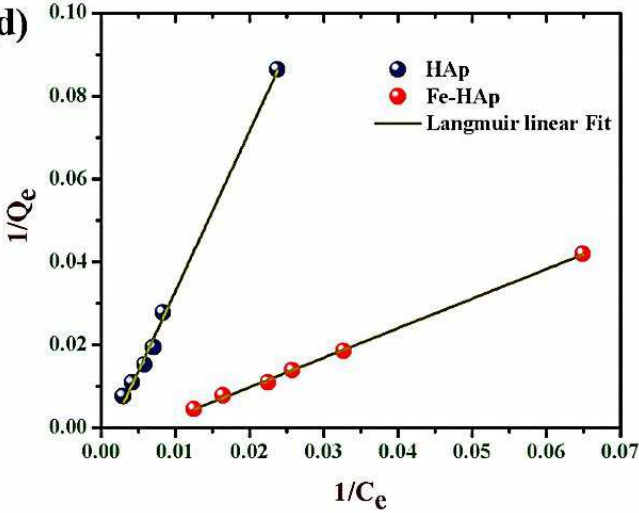

(f)

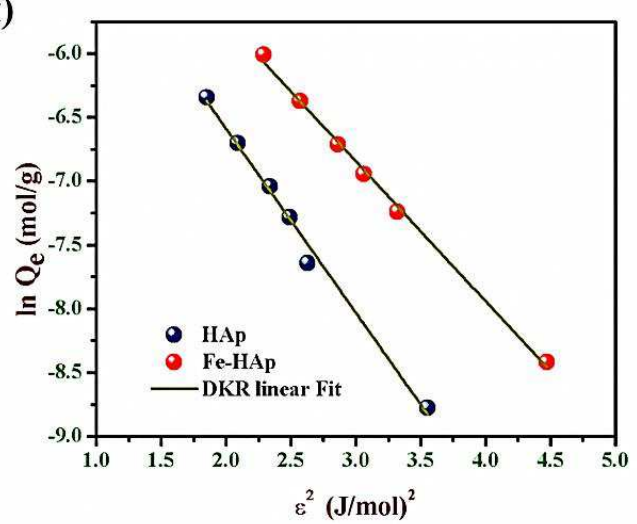

Fig. $5 \mathrm{As}^{3+}$ ion adsorption isotherms of HAp and Fe-HAp: (a) Pseudo $1^{\text {st }}$ order kinetics, (b) Pseudo $2^{\text {nd }}$ order kinetics, (c) Intra particle diffusion (d) Langmuir, (e) Freundlich, and (f) DKR 
Table 1. Adsorption isotherm of $\mathrm{As}^{3+}$ ion adsorption using HAp and Fe-HAp

\begin{tabular}{|c|c|c|c|}
\hline & \multicolumn{3}{|l|}{ Adsorbent } \\
\hline & & HAp & Fe-HAp \\
\hline & $\mathrm{Q}_{\exp }(\mu \mathrm{g} / \mathrm{g})$ & $132 \pm 5$ & $184 \pm 5$ \\
\hline \multirow{3}{*}{$\begin{array}{l}\text { pseudo-first-order } \\
\text { kinetics }\end{array}$} & $\mathrm{Q}_{\mathrm{m}}(\mu \mathrm{g} / \mathrm{g})$ & $83 \pm 3$ & $37 \pm 3$ \\
\hline & $\mathrm{K}_{1}\left(\min ^{-1}\right)$ & 0.036 & 0.047 \\
\hline & $\mathrm{R}^{2}$ & 0.9971 & 0.9360 \\
\hline \multirow[t]{3}{*}{ pseudo-second-order } & $\mathrm{Q}_{\mathrm{m}}(\mu \mathrm{g} / \mathrm{g})$ & $144 \pm 3$ & $188 \pm 3$ \\
\hline & $\mathrm{K}_{2}\left(\mu \mathrm{g} / \mathrm{g} \cdot \mathrm{min}^{-1}\right)$ & $28.9 \pm 1$ & $185 \pm 1$ \\
\hline & $\mathrm{R}^{2}$ & 0.9999 & 0.9999 \\
\hline \multirow{3}{*}{$\begin{array}{l}\text { Intra-particle } \\
\text { diffusion }\end{array}$} & $\mathrm{K}_{\mathrm{i}}\left(\mu \mathrm{g} / \mathrm{g} \min ^{1 / 2}\right)$ & $8.85 \pm 0.1$ & $3.20 \pm 0.1$ \\
\hline & $C_{i}(\mu g / g)$ & $71.94 \pm 1$ & $161.84 \pm 1$ \\
\hline & $\mathrm{R}^{2}$ & 0.9035 & 0.8314 \\
\hline \multirow[t]{4}{*}{ Langmuir isotherm } & $\mathrm{Q}_{\mathrm{m}}(\mu \mathrm{g} / \mathrm{g})$ & $139 \pm 3$ & $183 \pm 3$ \\
\hline & $\mathrm{K}_{\mathrm{L}}(\mu \mathrm{g} / \mathrm{L})$ & 3.85 & 0.71 \\
\hline & $\mathrm{R}_{\mathrm{L}}$ & $3.8 \mathrm{e}^{-3}$ & $7.11 \mathrm{e}^{-4}$ \\
\hline & $\mathrm{R}^{2}$ & 0.9966 & 0.9989 \\
\hline \multirow[t]{3}{*}{ Freundlich isotherm } & $\mathrm{K}_{\mathrm{F}}(\mu \mathrm{g} / \mathrm{g})$ & $7.31 \pm 2$ & $2.77 \pm 2$ \\
\hline & $1 / \mathrm{n}$ & 1.18 & 1.43 \\
\hline & $\mathrm{R}^{2}$ & 0.9932 & 0.9900 \\
\hline \multirow{4}{*}{ DKR } & $\mathrm{Q}_{\mathrm{m}}(\mu \mathrm{g} / \mathrm{g})$ & $127 \pm 2$ & $181 \pm 2$ \\
\hline & $\beta(\mathrm{mol} / \mathrm{J})^{2}$ & $-1.439 \mathrm{e}^{-9}$ & $-1.096 \mathrm{e}^{-9}$ \\
\hline & $\mathrm{E}(\mathrm{kJ} / \mathrm{mol})$ & $18.6 \pm 0.1$ & $21.3 \pm 0.1$ \\
\hline & $\mathrm{R}^{2}$ & 0.9907 & 0.9970 \\
\hline
\end{tabular}

*Qexp is experimental adsorption capacity $(\mu \mathrm{g} / \mathrm{g})$ 
Table 2. Comparison of Literature review of Arsenic adsorption capacity and affinity

\begin{tabular}{|c|c|c|c|c|c|c|}
\hline Adsorbent & $\begin{array}{l}\text { Time } \\
(\min )\end{array}$ & & $\begin{array}{l}\text { Capacity } \\
(\mathrm{mg} / \mathrm{g})\end{array}$ & Arsenic & $\begin{array}{l}\text { Affinity } \\
(\mathrm{mg} / \mathrm{L})\end{array}$ & Ref \\
\hline Iron-oxide-coated quartz (IOCQ) & 1440 & 6 & 0.097 & $\mathrm{As}^{5+}$ & -- & [18] \\
\hline Biochar & 1440 & 7 & 0.422 & $\mathrm{As}^{5+}$ & 41.49 & [19] \\
\hline Magnetic Fe-hydrotalcite & 15 & 9 & 0.121 & $\mathrm{As}^{3+}$ & 0.004 & [20] \\
\hline Activated alumina & 360 & 7.6 & 0.180 & $\mathrm{As}^{3+}$ & 0.117 & [21] \\
\hline $\begin{array}{l}\text { Sulfate-modified iron oxide-coated } \\
\text { sand }\end{array}$ & 480 & 7.2 & 0.096 & $\mathrm{As}^{3+}$ & 0.326 & [22] \\
\hline Fe-HAp (Iron-Hydroxyapatite) & 1 & 7 & 0.183 & $\mathrm{As}^{3+}$ & $7.11 \mathrm{e}^{-4}$ & This work \\
\hline
\end{tabular}

\section{Highlights}

1. Enhanced colloidal stability and surface area due to $\mathrm{Fe}^{2+}$ doped in HAp lattice

2. Dopant $\mathrm{Fe}^{2+}$ drastically reduced the particle size of $\mathrm{HAp}(\mathrm{L}=400 \%$ and $\mathrm{W}=225 \%)$

3. Rapid removal of highly toxic $\mathrm{As}^{3+}$ ion at trace level $(1 \mathrm{~min})$

4. $\mathrm{As}^{3+}$ adsorption affinity higher (83-99.9\%) than previous reports

5. No secondary toxic sludge were observed during adsorption 


\section{Supplementary Files}

This is a list of supplementary files associated with this preprint. Click to download.

- Supplementarydetails.docx 